\title{
Implementation of maintenance employees’ work time scheduling
}

Michał Zasadzień * , Bartosz Szczęśniak, Bożena Skotnicka-Zasadzień

Silesian University of Technology, Institute of Production Engineering, Poland

*Corresponding author: Michał Zasadzień, PhD., michal.zasadzien@polsl.pl

\begin{abstract}
The article presents the method of scheduling work time for maintenance workers. The purpose of the method is to implement the scheduling process in organizations where it has not been used, and the maintenance work consists only in removing failures. The method uses a scheduling table, helpful in scheduling and performance monitoring, and a spreadsheet-based IT tool that analyzes the data collected. The proposed method makes it easy to implement work time scheduling and monitor key performance indicators for maintenance workers.
\end{abstract}

Key words: maintenance; excel; planned; scheduling; IT; support

\section{Introduction}

Effectively functioning maintenance teams should ensure failure-free work of machines and, in consequence, production continuity, the required quality of products, the efficiency of machines and the safety of their operators ${ }^{1}$. However, in the era of ever-increasing competitiveness an equally important aspect is continuous reduction of production costs. One of production cost reduction methods is to constantly increase the effectiveness of work, including the work of maintenance employees.

In the article a tool which allows implementing the process of maintenance technicians' work scheduling has been demonstrated. The presented method is based on the concept of assignment, which involves assigning particular tasks (planned works) to available resources (maintenance employees) in a way that ensures minimal total costs or time necessary to perform a planned action and on the assumption that one employee can perform only one task at a given time ${ }^{2}$.

\section{Method descriptions}

The proposed method of time working scheduling is very simple in its implication and can be applied in organisations with a poorly developed IT system to support the maintenance 
department work. Its basic element is a visual table of scheduling and an IT tool designed for data analysis, which is based on commonly available spreadsheets, e.g. MS Excel, OpenOffice.org Calc etc.

The first stage of the method implementation is developing a database of errors, i.e. a list of difficulties which make it impossible to perform the planned works within a specified time and their designation (error codes). Before starting a week's work, a list of planned works with their estimated duration should be prepared and provided to relevant workers.

Another stage involves creating a table of works scheduling, which consists of: a list of employees, day of the week, working hours and rows marked as $\mathrm{P}$ - planning of works, R real performance and B - potential mistakes. At the end of the table there are a total number of planned hours that were carried out and the number of overtime hours.

In the third stage the foreman and the workers complete the table. At the beginning of the week the foreman circles tasks to be performed by a relevant employee in row $\mathrm{P}$, with accuracy to 1 hour. Having done the task, the employee circles the real time of its duration. If the duration or commencement of the task does not comply with the planned one, the worker enters the error code in row B. In the event the working time needs to be prolonged, also the number of each worker's overtime hours in a given week is recorded. A completed table has been presented in Fig. 1.

\begin{tabular}{|c|c|c|c|c|c|c|c|c|c|c|c|c|c|c|c|c|c|c|c|c|c|}
\hline \multirow{2}{*}{ Employee } & & \multicolumn{6}{|c|}{ Day 1} & \multicolumn{7}{|c|}{$\ldots$} & \multicolumn{6}{|c|}{\begin{tabular}{|c|} 
Day N \\
\end{tabular}} & \multirow{2}{*}{$\begin{array}{|ll|}\mathrm{P} / & \mathrm{R} \\
& \\
\end{array}$} \\
\hline & & 1 & 23 & \begin{tabular}{|l|l|l|}
4 & 5 \\
\end{tabular} & \begin{tabular}{|l|l|l}
6 & 7 \\
\end{tabular} & 8 & \begin{tabular}{l|l|l|}
9 & 10 & 1112 \\
\end{tabular} & 1 & \begin{tabular}{|l|l|}
2 & 3 \\
\end{tabular} & \begin{tabular}{l|l|l}
3 & 4 & 5 \\
\end{tabular} & \begin{tabular}{l|l|}
5 & 6 \\
\end{tabular} & 78 & 89 & 101112 & \begin{tabular}{|l|l|}
12 \\
\end{tabular} & 34 & \begin{tabular}{l|l}
4 & 5 \\
\end{tabular} & \begin{tabular}{l|l}
67 \\
67
\end{tabular} & \begin{tabular}{ll|}
7 & 8 \\
\end{tabular} & 9101112 & \\
\hline & $\mathrm{P}$ & & & & & & & & & & & & & & & & & 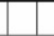 & & & \\
\hline & $\mathrm{R}$ & & & & & & & & & & & & & & & & & & & & \\
\hline & $B$ & & & B 01 & & & & & $B$ & 051 & & & & & & & & & & & \\
\hline & $\mathrm{P}$ & & & & & & & & & & & & & & & & & & & & \\
\hline & $\mathrm{R}$ & & & & & & & & & & & & & & & & & & & & \\
\hline & $B$ & & & & & & & & & & & & & & & & & & & & \\
\hline
\end{tabular}

Fig. 1 - Table of planned works

\section{Results and Discussions}

To enable an analysis of data collected as a result of using the described method, it was necessary to create an appropriate IT tool. MS Excel spreadsheet was used for this purpose. It has been established that the proposed tool should allow collecting all the data as well as generating the desired reports. For the problem in question the following entities have been identified: “Employee”, “Day”, “Week”, “Year”, “Task”, “Error”, “Employee’s task on weekday", "Employee in week". Attributes identified for particular entities and correlations between them have been presented by means of a model compliant with IDEFX1 standard in Fig. 2. 


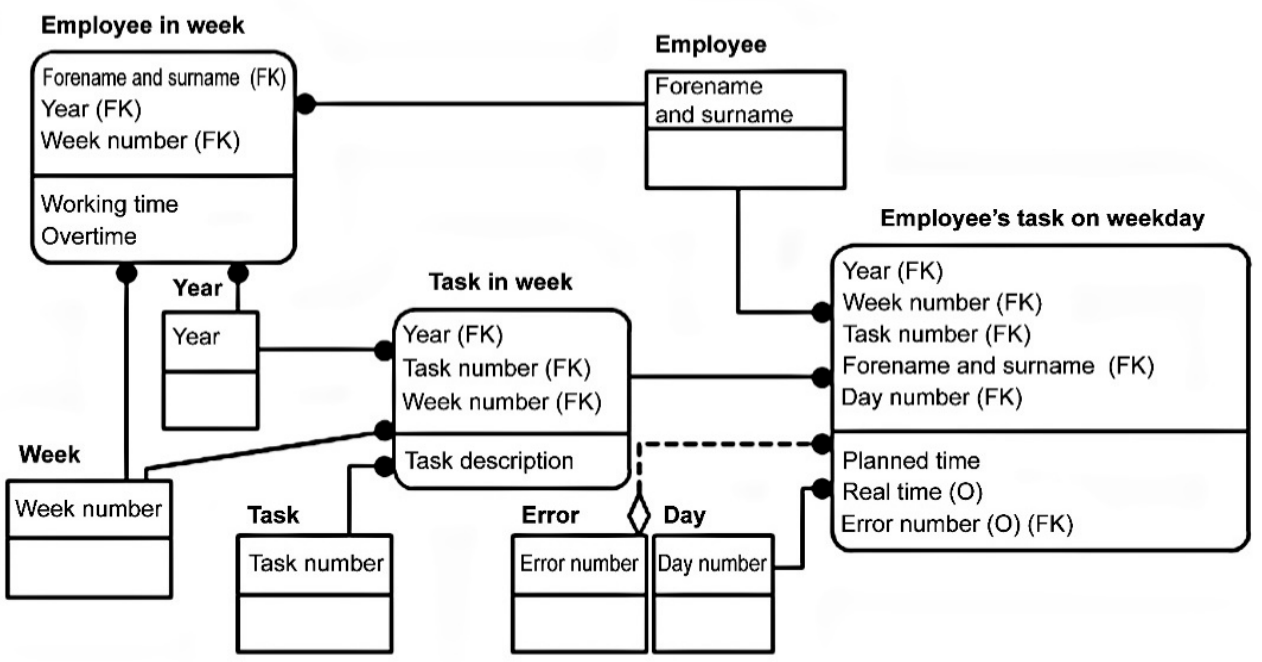

Fig. 2 - Attributes and correlations between the identified entities

In the created tool the "Task in week" entity is represented in the form contained in spreadsheet "Z” of a traditional table illustrated in Fig. 3.

\begin{tabular}{c|c|c|c|l|}
\hline \hline & B & C & D & \multicolumn{1}{|c|}{ E } \\
\hline 1 & Year & Week & Task_no & Task description \\
\hline 2 & 2012 & 42 & 1 & Description - Task 1 \\
\hline 3 & 2012 & 42 & 2 & Description - Task 2 \\
\hline
\end{tabular}

Fig. 3 - A table representing the „Task in week” entity

Currently entities such as „Employee”, „Day”, “Week”, “Year”, “Task”, “Error” serve as a dictionary. They have been introduced to limit the value of other entities entered for attributes. Each of them has only one attribute, which is a basic key. However, the number of attributes at each moment can be extended by means of one-column tables placed in spreadsheet " $D$ ”. In a traditional form of the table, the "Employee's task on weekday” entity cannot be represented in the tool. According to the user's requirements, relevant values must be entered in the form, a fragment of which can be seen in Fig. 4. The occurrence of the entity is identified here by: year, week number as well as the employee's forename and surname, entered in columns A, B and C; number of weekday entered in E2:CJ2 cells; task number entered in a relevant row in one of E:CJ columns.

In three cells placed below the cell containing the task number, values of such attributes as planned time, real time and potential error code are entered for a given entity occurrence. 


\begin{tabular}{|c|c|c|c|c|c|c|c|c|c|c|c|c|c|c|c|c|}
\hline 4 & A & B & c & D & E & $\mathrm{F}$ & G & $\mathrm{H}$ & Q & $\mathrm{R}$ & 5 & T & BY & CJ & CK & $\mathrm{CL}$ \\
\hline 2 & & & & & 1 & 1 & 1 & 1 & 2 & 2 & 2 & 2 & 7 & 7 & & \\
\hline 3 & & & & & \multicolumn{4}{|c|}{ Day 1} & \multicolumn{4}{|c|}{ Day 2} & \multicolumn{2}{|c|}{ Day 7} & & \\
\hline 4 & Year $=$ & Week . & Employee - &. & 1 & 2 & 3 & 4 & 1 & 2 & 3 & 4 & 1 & 12 & Time & Overtime \\
\hline 5 & 2012 & 42 & $A b c$ De & Task_no & 8 & 1 & 3 & & 3 & 6 & & & 9 & & 43 & 3 \\
\hline 6 & 2012 & 42 & $A b c D e$ & Time_p & 2 & 3 & 1 & & 4 & 3 & & & 4 & & & \\
\hline 7 & 2012 & 42 & $A b c D e$ & Time_R & 6 & 2 & 1 & & 4 & 4 & & & 5 & & & \\
\hline 8 & 2012 & 42 & Abc De & Error_no & 25 & 33 & & & & 17 & & & 25 & & & \\
\hline 9 & 2012 & 42 & Fgh Jk & Task_no & 8 & 5 & & & 2 & 8 & & & 9 & & 42 & 2 \\
\hline
\end{tabular}

Fig. 4 - Representation of the „Employee’s task on weekday” and „Employee in week” entities

The form presented in Fig. 4 also contains representation of the "Employee in week" entity. In this case the layout is similar to the traditional database table, but due to the construction of the form, subsequent values are entered in every fourth row. Values entered in all the above mentioned areas must be interrelated. The values of attributes that are foreign keys must be consistent with the values of respective basic keys. This integrity has been obtained using a Name Manager and Data Valuation mechanism, similarly to the solutions proposed in literature $^{3}$. It has been established that all reports required by the method can be prepared using pivot tables created on the basis of data contained in a pivot table presented in Fig. 5.

\begin{tabular}{|c|c|c|c|c|c|c|c|c|c|c|c|}
\hline & $F$ & G & H & I & \lrcorner & K & L & M & N & O & P \\
\hline 1 & Year & Week & Day & Employee & Task_no & Time_P & Time_R & Error_no & Task_decsription & Time & Overtime \\
\hline 2 & 2012 & 42 & 1 & Abc De & 8 & 2 & 6 & 25 & Description - Task 8 & 43 & 3 \\
\hline 3 & 2012 & 42 & 1 & Abc De & 1 & 3 & 2 & 33 & Description - Task 1 & 43 & 3 \\
\hline
\end{tabular}

Fig. 5. A table for creating the required reports

If all the entities were represented in a spreadsheet in the form of traditional tables, like in a typical database, obtaining a data layout consistent with Fig. 5 would not be a big problem. For this purpose, it would be possible to use a solution similar to the ones proposed in literature ${ }^{4,5}$. However, due to the manner of representing the "Employee’s task on weekday" entity, the problem is more complex. It is necessary to create a mechanism which will transfer subsequent entities from the proposed form to the table presented in Fig. 7. An appropriate mechanism has been created by using only the in-built functions of MS Excel spreadsheet. The proposed solutions can be divided into two parts. The first part, contained in spreadsheet „H”, has been presented in Fig. 6. The other part, contained in spreadsheet "T”, which contains a table shown in Fig. 5, has been presented in Fig. 7. In spreadsheet " $H$ ", the CU5:FZ5044 area, whose cells correspond to the cells of E5:CJ5044 area of the form presented in Fig. 6, has been separated. In this area, as a result of using F01 and F02 formulas, by means of subsequent natural numbers areas which contain subsequent occurrences of the “Employee’s task on weekday” entity have been marked. These areas are cells containing the 
entered task number. Due to the efficiency of the created tool, formula FF02 has been introduced only in rows in which these numbers are entered.

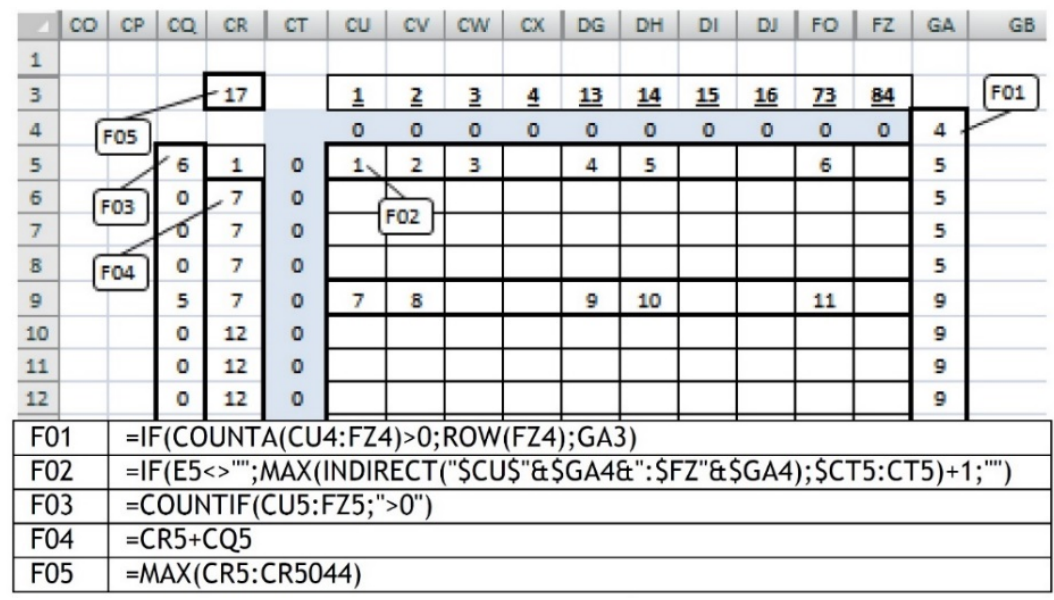

Fig. 6. The proposed solution - a layout of formulas in spreadsheet „H”

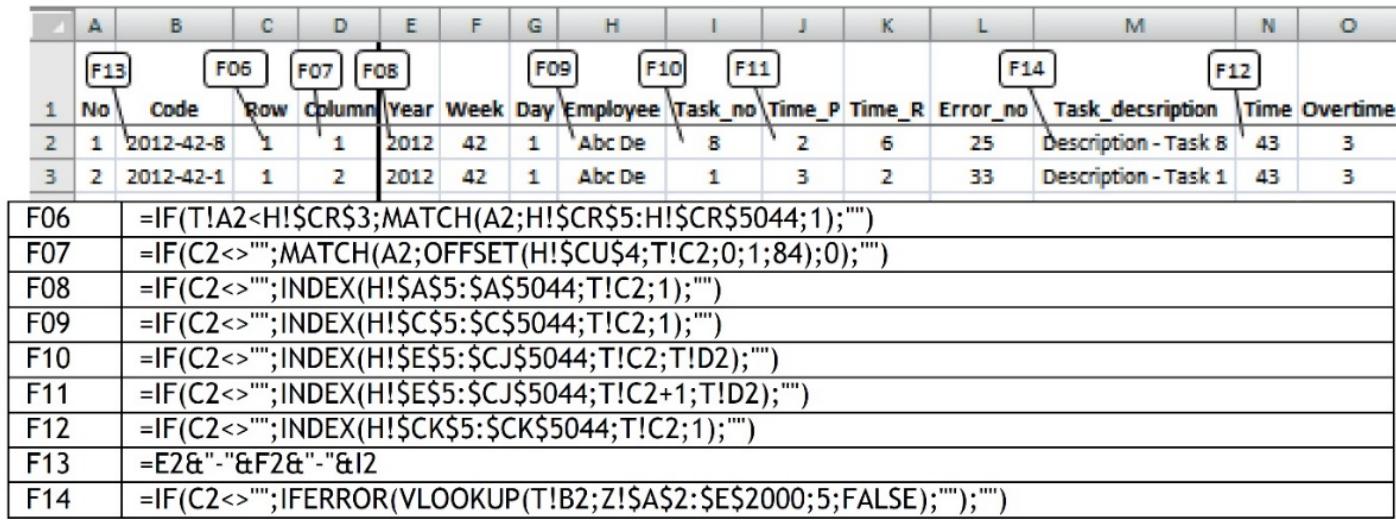

Fig. 7. The proposed solution - a layout of formulas in spreadsheet „T”

Next, using formulas F03-F12, respective values are transferred to the target table contained in spreadsheet "T" (fig. 7). Due to a considerable resemblance of particular formulas, in this article only the formulas transferring selected values have been presented. Finally, using formulas F13-F14, respective descriptions of particular tasks are transferred to the target table. To ensure proper functioning of formula F14, in spreadsheet "Z" in column "A", a formula generating a code with a structure compliant with the code from column " $\mathrm{B}$ " of spreadsheet “T” has been introduced.

\section{Conclusions}

The presented method of scheduling work time for maintenance workers simplifies the process of deploying work schedules in an organization that have so far been in the "failure- 
to-failure" system, it is very easy and cheap to implement - does not require large enterprise resources, data analysis is done through simple IT tools available in every enterprise.

According to the current tendency that the largest percentage of maintenance works was scheduled, the most important indicators that can be easily achieved through the proposed method are, above all, Craft Utilization, Craft Performance, Proactive Work Capacity index. Improvement of the maintenance process can begin with analyzing the causes of errors in the untimely execution of scheduled tasks. Monitoring of the CU, CP and PWCi indicators should result in a permanent increase in share of work planned throughout the maintenance work period, thereby reducing the number of failures and improving the efficiency of use of machines present in the manufacturing process.

\section{Acknowledgements}

This article is the result of research conducted at the Institute of Production Engineering, Faculty of Organization and Management, Silesian University of Technology, within the statutory work entitled "Methods and tools for improving products and services on the selected examples" (symbol 13/030/BK_17/0027).

\section{References}

1. M. Molenda, Rating of quality management in selected industrial companies, Scientific Journals Maritime University of Szczecin 27 (2011) 105-111.

2. B. Filipowicz, Badania operacyjne: Wybrane metody obliczeniowe i algorytmy. Poldex, Kraków, 1999.

3. B. Szczęśniak, A. Bujanowska, Koncepcja zastosowania arkusza kalkulacyjnego do wspomagania realizacji procesu diagnostyki i napraw w wybranym szpitalu, in W. Biały, J. and Kaźmierczak (eds.), Systemy Wspomagania w Inżynierii Produkcji, PKJS, Gliwice, 2012, 78-91.

4. J. Tyszkiewicz, Spreadsheet as a relational database engine, International Conference on Management of data ACM SIGMOD, Indianapolis, IN, USA (2010), 195-206.

5. B. Szczesśniak, Concept of supportive spreadsheet application in the survey of production departments' satisfaction with services of maintenance departments, Scientific Journals Maritime University of Szczecin, 32 (2012), 91-96. 